\title{
The WSN Real-Time Monitoring System for Agricultural Products Cold-Chain Logistics
}

\author{
Chen Liu ${ }^{2}$, Ruirui Zhang ${ }^{1,3}$, Tian'en Chen ${ }^{1, *}$, and Tongchuan $\mathrm{Yi}^{4}$ \\ ${ }^{1}$ National Engineering Research Center for Information Technology in Agriculture, \\ Beijing 100097, China \\ ${ }^{2}$ College of Mechanical and Electronic Engineering, Northwest A \& F University, \\ Shaan xi, Yangling 712100, China \\ ${ }^{3}$ College of Information and Electrical Engineering, China Agricultural University, \\ Beijing 100083, China \\ ${ }^{4}$ College of Information Engineering, Capital Normal University, Beijing 100048, China \\ xmyliuchen@126.com, \{zhangrr, chente\}@nercita.org.cn, \\ y_t_chealiyun.com
}

\begin{abstract}
In order to reduce the loss of fresh agricultural products and to ensure the food safety in the process of cold chain logistics, a real-time monitoring wireless sensor network system, based on Zigbee technology for agricultural products cold-chain logistics is proposed. The sensor node is designed with CC2530 SOC and SHT15 sensor, in which the communication stack is optimized and a sleep-wake up mechanism is designed. By analyzing the experimental test and actual application, it shows that the system has a good performance in low power consumption and is satisfied with cold chain logistics application.
\end{abstract}

Keywords: cold chain logistics monitoring, transportation of agricultural products, wireless sensor network.

\section{Introduction}

In China, agricultural products consumption is 400 million each year. It accounts for over $50 \%$ of the total consumption [1]. As a special commodity, agricultural products including fruit, meat, vegetables, eggs and aquatic products is fresh and perishable. In order to ensure the safety of agricultural products and to reduce logistics losses, agricultural products have to be handled under controlled environmental quantities such as temperature and humidity. So cold chain logistics is used in agricultural products transportation. The chain that brings the temperature-sensitive products from the factory to the consumer through an uninterrupted series of steps under a controlled temperature is usually called the cold chain [2]. Some thermal requirements have to be installed in the refrigerated vehicles to avoid the situation that may occur could cause a significant change in the product temperature during the transportation. Wireless sensor network is one of the best ways to solve this problem [3-4].

A wireless sensor network consists of spatially distributed autonomous sensors to monitor physical or environmental conditions, and to cooperatively pass their data

* Corresponding author.

D. Li and Y. Chen (Eds.): CCTA 2013, Part II, IFIP AICT 420, pp. 255-261, 2014.

(C) IFIP International Federation for Information Processing 2014 
through the network to a main location. The main characteristics of a WSN include low-power consumption and mobility of nodes [5-7]. On the one hand, it can improve the reliability and flexibility of the system. On the other hand, nodes using batteries can be worked for a long time.

In that case, this paper proposes a wireless sensor network system of cold chain logistics based on Zigbee technology. The sensor node is designed with CC2530 SOC and SHT15 sensor, in which the communication stack is optimized and a sleep-wake up mechanism is designed. The testing results shows that the system is suitable for cold chain logistics.

\section{Hardware Design of Wireless Sensor Node}

The WSN is built of nodes. According to the function, wireless sensor node can be classified as sensor node and coordinator. The hardware structure of the coordinator is similar and more simple than the sensor node, so this article put emphasis on the hardware design of the monitoring node.

Each sensor node is typically composed of five parts: a radio transceiver with an internal antenna or connection to an external antenna, a microcontroller, an electronic circuit for interfacing with the sensors and an energy source, usually a battery or an embedded form of energy harvesting [8]. Considering the practical requirements of the agricultural products cold chain logistics, this paper chooses CC2530 chip as a processor and wireless communication solution. Sensor module is included SHT15 temperature and humidity sensor. Two batteries can be the enough power source. Fig.1 shows the structure of sensor node.

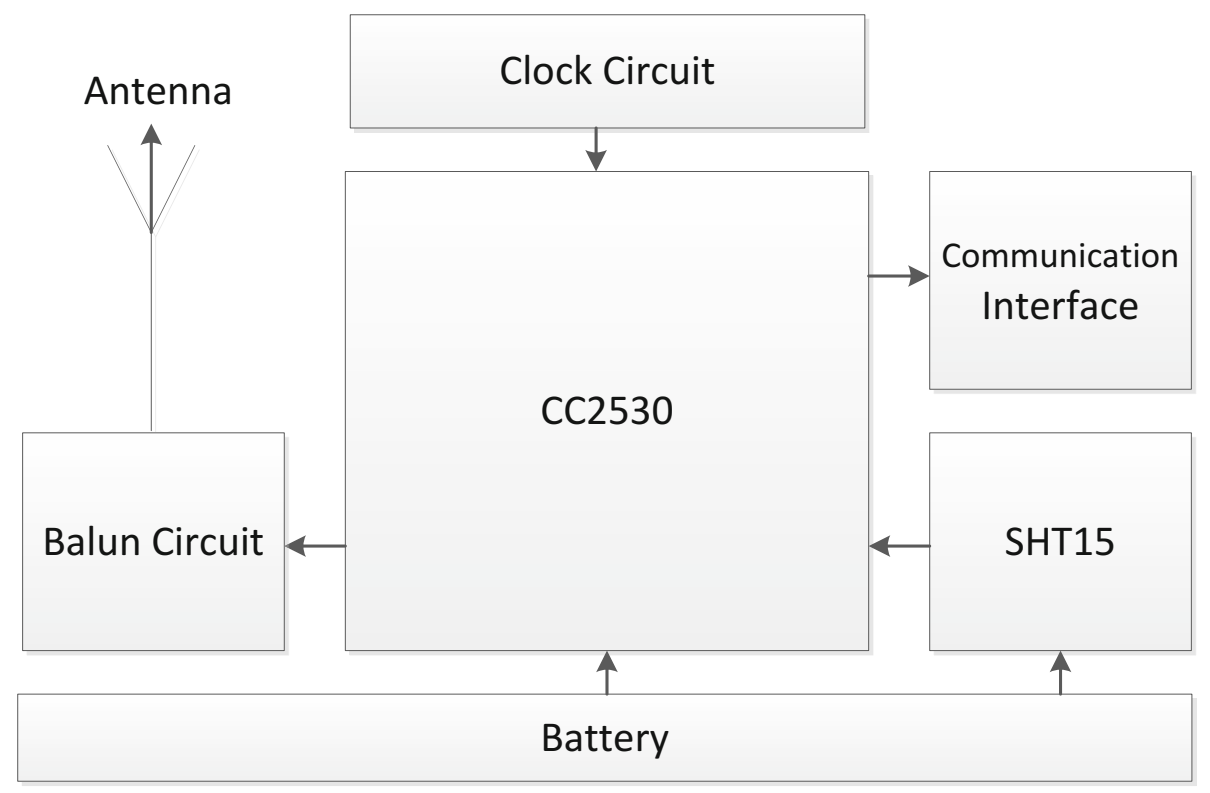

Fig. 1. The structure of sensor network node 
CC2530 is a true system-on-chip (SoC) solution for IEEE 802.15.4 and Zigbee applications. It combines the excellent performance of a leading RF transceiver with an industry-standard enhanced $8051 \mathrm{MCU}$, in-system programmable flash memory, 8-KB RAM, and many other powerful features. The operating ambient temperature range is from $40{ }^{\circ} \mathrm{C}$ to $125{ }^{\circ} \mathrm{C}$ and the operating supply voltage is from $2.0 \sim 3.6 \mathrm{~V}$ [9]. The CC2530 has various operating modes, making it highly suited for systems where ultralow power consumption is required. Short transition times between operating modes further ensure low energy consumption. The core current consumption is about $1 \mu \mathrm{A}$ in power mode 2 which need only $1 \mathrm{~ms}$ to be active [10].

SHT15 is Sensirion's family of surface mountable relative humidity and temperature sensors. The sensors integrate sensor elements plus signal processing on a tiny foot print and provide a fully calibrated digital output. A unique capacitive sensor element is used for measuring relative humidity while temperature is measured by a band gap sensor. Both sensors are seamlessly coupled to a 14 bit analog to digital converter and a serial interface circuit. The operating Range is from $40{ }^{\circ} \mathrm{C}$ to $123.8{ }^{\circ} \mathrm{C}$ and the resolution is $\pm 2.0 \%$ and $\pm 0.3{ }^{\circ} \mathrm{C}$. The average power consumption is only $90 \mu \mathrm{W}$ [11].

\section{Software Architecture}

The software architecture is based on Z - Stack operating system in IAR Embedded Workbench development environment with $\mathrm{C}$ language. Z-Stack operating system is semi-open systems based on priority developed by TI for CC2530 SoC [12]. Monitoring functions can be realized by adding definition pins of CC2530 and SHT15 in hardware abstraction layer and writing appropriate programs in application layer.

System nodes complete initialization including system clock, stack, hardware, operating system and so on. After the initialization system start to query task events with priority followed by entering into MAC layer, network layer, hardware layer, application support sub-layer and application layer.

If any event of binding time happens in application layer, sensor node reset SHT15 sensor and start to collect data. Data collection includes two parts which are the temperature and the humidity. The monitoring node sends data to coordinator after collecting. Then, the monitoring node enters into sleep mode to save power and refresh the timer.

CC2530 has three kinds of sleep modes: PM1, PM2 and PM3. Sensor node works in PM1 mode normally. PM2 mode is used to save power consumption and can be awakened periodically. PM3 mode has the least power consumption but it can be awakened by external interrupt only. In this paper, the function of "DRFD_RCVC_ALWAYS_ON" is defined as false. Sleep-wake up mechanism program can be realized by adding function of "POWER_SAVING" at the end of each application program. The flow chart of execution is shown in fig 2. 


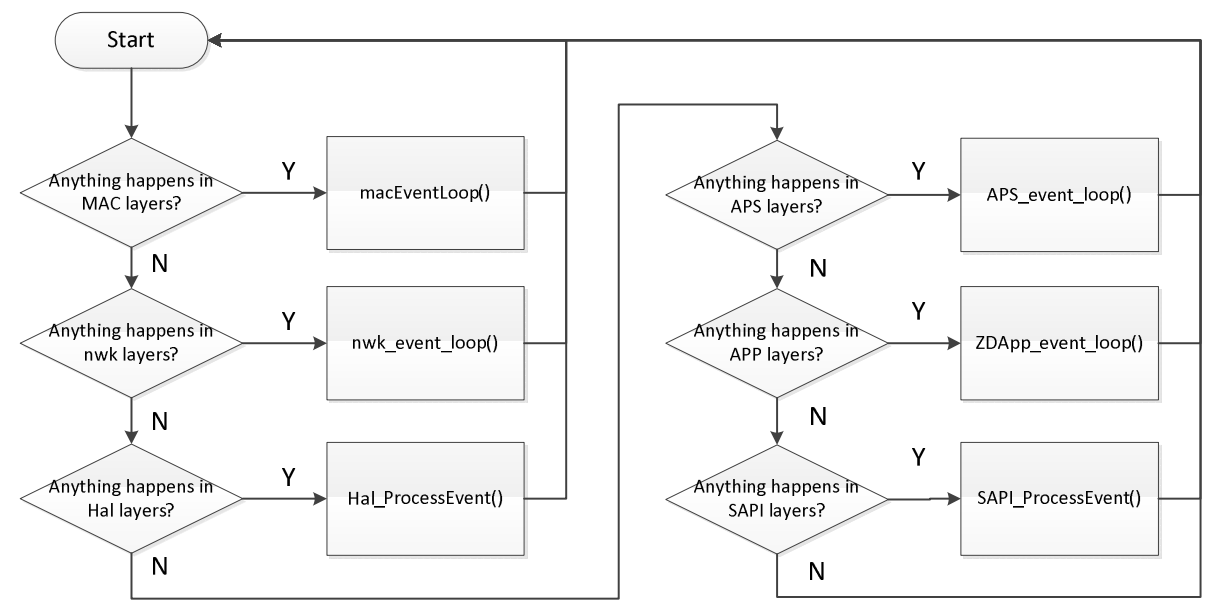

Fig. 2. Flow chart of monitoring node data acquisition

\section{$4 \quad$ Testing and Results Analysis}

For verification the system has been tested with two sensor nodes measuring the temperature and humidity at two different positions. SmartRF Studio 7 software developed by TI company is used for testing RSSI of sensor node and packet loss rate. The communication radio frequency is $2405 \mathrm{MHz}$. Sensor node sends 300 data in eight different distances with ten levels of emission power. The averaged results are showed in Table 1 and Table 2.

Table 1. Testing results of RSSI (dBm)

\begin{tabular}{ccccccccc}
\hline Power & \multicolumn{7}{c}{ Distance/m } \\
\cline { 2 - 8 }$/ \mathrm{dBm}$ & 1 & 5 & 10 & 15 & 20 & 30 & 40 & 50 \\
\hline 4.5 & -54.9 & -64.0 & -69.9 & -72.7 & -80.0 & -85.5 & -87.1 & -94.9 \\
2.5 & -57.0 & -66.2 & -71.7 & -74.6 & -85.6 & -86.5 & -89.5 & -98.7 \\
1.0 & -61.6 & -66.5 & -72.3 & -77.7 & -89.3 & -92.4 & -92.0 & -99.4 \\
-0.5 & -63.8 & -68.1 & -73.7 & -81.5 & -92.5 & -93.3 & -92.7 & -98.0 \\
-1.5 & -66.5 & -69.7 & -75.4 & -83.1 & -94.0 & -93.6 & -95.1 & -100.3 \\
-4.0 & -68.0 & -74.1 & -79.8 & -86.8 & -94.4 & -97.1 & -98.5 & \\
-8.0 & -68.9 & -76.1 & -83.7 & -89.3 & -95.2 & -98.4 & -99.3 & \\
-12.0 & -72.2 & -84.5 & -86.8 & -92.2 & -98.0 & -99.4 & & \\
-16.0 & -77.0 & -84.1 & -92.0 & -95.4 & -100.2 & & & \\
-20.0 & -80.3 & -87.8 & -95.0 & -97.2 & & & & \\
\hline
\end{tabular}

Note: the blank space means node could not receive the signal. 
Table 2. Testing results of packet losing rate (\%)

\begin{tabular}{ccccccccc}
\hline Power & \multicolumn{7}{c}{ Distance $/ \mathrm{m}$} \\
\cline { 2 - 8 }$/ \mathrm{dBm}$ & 1 & 5 & 10 & 15 & 20 & 30 & 40 & 50 \\
\hline 4.5 & 0 & 0 & 0 & 0 & 0.5 & 0.7 & 1.3 & 2.9 \\
2.5 & 0 & 0 & 0 & 0 & 1.0 & 1.1 & 2.3 & 53.2 \\
1.0 & 0 & 0 & 0 & 0.2 & 1.7 & 2.7 & 3.4 & 51.6 \\
-0.5 & 0 & 0 & 0.2 & 0.6 & 3.8 & 7.2 & 8.7 & 61.8 \\
-1.5 & 0 & 0 & 0.1 & 0.8 & 7.5 & 7.3 & 9.2 & 92.5 \\
-4.0 & 0 & 0 & 0.3 & 0.8 & 14.0 & 27.2 & 42.0 & 100 \\
-8.0 & 0 & 0 & 0.7 & 1.6 & 20.0 & 50.7 & 78.8 & 100 \\
-12.0 & 0 & 0.8 & 0.7 & 1.8 & 33.1 & 71.5 & 100 & 100 \\
-16.0 & 0 & 1.1 & 4.2 & 4.6 & 96.7 & 100 & 100 & 100 \\
-20.0 & 0.3 & 4.2 & 7.1 & 20.0 & 100 & 100 & 100 & 100 \\
\hline
\end{tabular}

Test results show that RSSI attenuation trend is obvious related with the decrease of transmitted power. When the distance becomes longer, RSSI becomes weak and the packet loss rate begins to rise. Packet loss phenomenon is obvious when the RSSI reduced to $-100 \mathrm{dBm}$. Within the scope of $15 \mathrm{~m}$, even - $16 \mathrm{dBm}$ transmitted power can guarantee less than $5 \%$ packet loss rate. But only transmitted power is $4.5 \mathrm{dBm}$ sensor node can guarantee the communication reliable. The wireless link is more reliable only if the communication distance is limited in a reasonable scope with a strong transmitted power. The comparison chart of RSSI and packet loss rate is showed in Fig.3 and Fig.4.

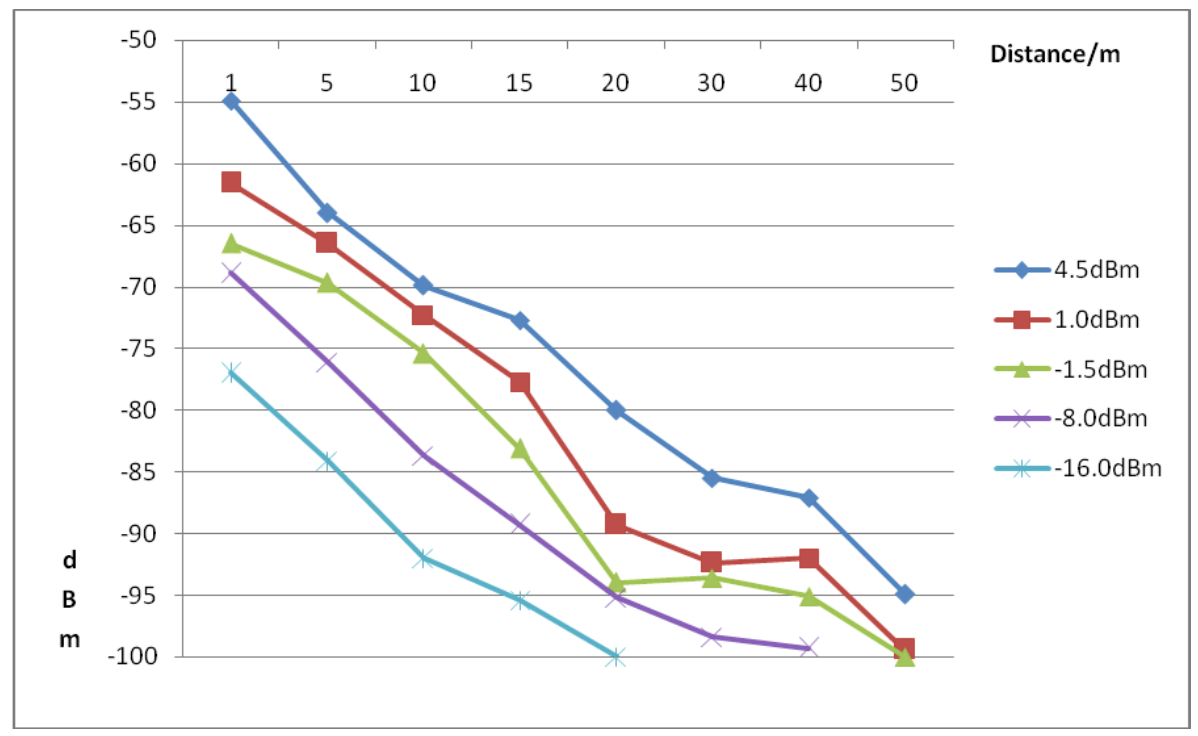

Fig. 3. Comparison chart of RSSI 


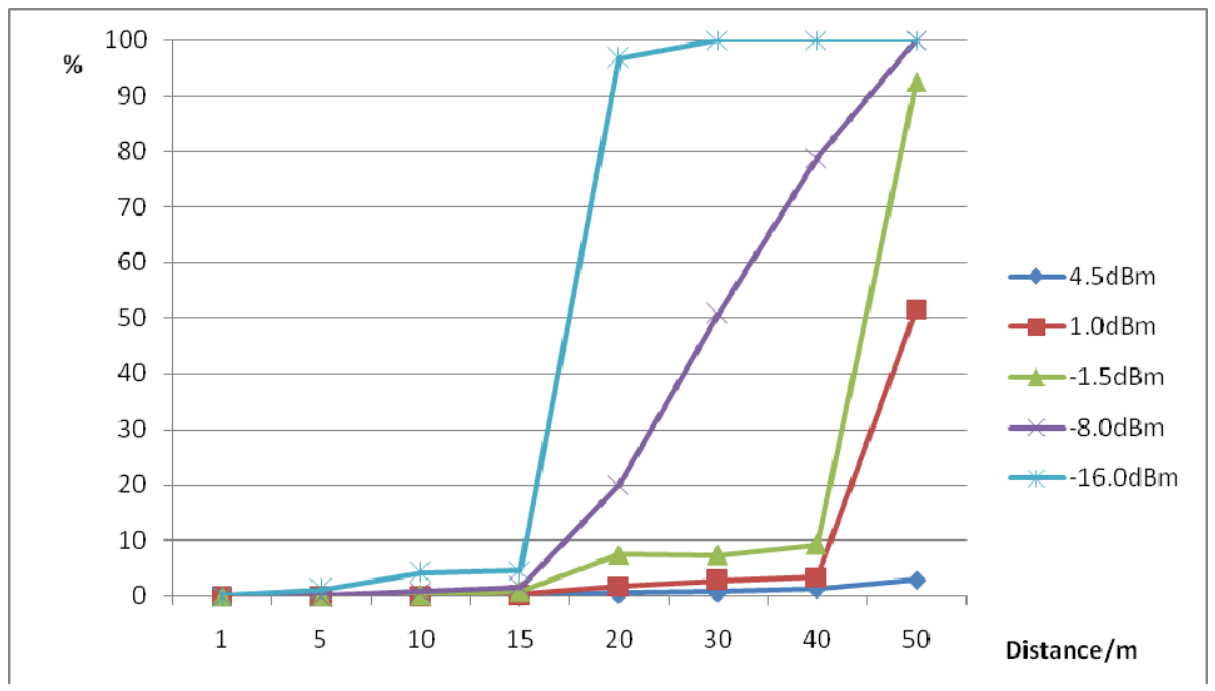

Fig. 4. Comparison chart of packet losing rate

The comparison results show that RSSI is above - $95 \mathrm{dBm}$ and packet loss rate is controlled within $8 \%$ when the distance limited to $30 \mathrm{~m}$ and the transmitted power above $-1.5 \mathrm{dBm}$. According to the actual situation, the distance between sensor nodes is no more than $20 \mathrm{~m}$. It proves that the system can be applied in cold chain logistics and the communication is reliable.

\section{Conclusions}

In this paper, a measuring system that is conceived for the monitoring of the temperature-sensitive products during their distribution has been proposed. The system consists of nodes based on CC2530 SoC and SHT15 sensor that are able to carry out measurements of the temperature and humidity around the monitored products. The testing shows that system performed well when the transmitting power is above - 1.5 $\mathrm{dBm}$. The RSSI can ensure over $-95 \mathrm{dBm}$ and packet loss rate is less than $10 \%$ in the range of $30 \mathrm{~m}$. The obtained results prove the effectiveness of the proposed solution. The system can be used in a variety of practical applications.

Acknowledgment. This work is supported in part by Research Key Technology R\&D Program of China under grant No. 2012AA101901, Beijing Natural Science Foundation under grant No. 4121001, and Research Foundation for Young Scholar of BAAFS under grant "WSN research and equipment development for its application in greenhouse group monitor”(No. QNJJ201217). 


\section{References}

1. Zhu, C.: Study on Farm Products Cold-chain Logistics System of China. Journal of Anhui Agriculture Science 39(4), 2317-2318 (2011)

2. Ruiz-Garcia, L., Barreiro, P., Robla, J.I., et al.: Testing ZigBee motes for monitoring refrigerated vegetable transportation under real conditions. Sensors 10(5), 4968-4982 (2010)

3. Strazdins, G., Elsts, A., Nesenbergs, K., et al.: Wireless Sensor Network Operating System Design Rules Based on Real-World Deployment Survey. Journal of Sensor and Actuator Networks 2(3), 509-556 (2013)

4. Lakshmil, V.R., Vijayakumar, S.: Wireless Sensor Network based Alert System for Cold Chain Management. Procedia Engineering 38, 537-543 (2012)

5. Heidmann, N., Janßen, S., Lang, W., et al.: Implementation and Verification of a Low-Power UHF/LF Wireless Sensor Network as Part of the Intelligent Container. Procedia Engineering 47, 68-71 (2012)

6. Sun, Y., Yang, H., Liu, Z., et al.: An Intelligent Logistics Tracking System Based on WSN. Journal of Computer Research and Development 48, 343-349 (2011)

7. Guo, B., Zhang, T., Qian, J., et al.: Design of Zigbee-based W ireless Information Collection Node For Cold Chain. Chinese Agricultural Science Bulletin 26(5), 318-321 (2010)

8. Ruiz-Garcia, L., Lunadei, L., Barreiro, P., et al.: A review of wireless sensor technologies and applications in agriculture and food industry: state of the art and current trends. Sensors 9(6), 4728-4750 (2009)

9. Hwang, J., Yoe, H.: Study of the ubiquitous hog farm system using wireless sensor networks for environmental monitoring and facilities control. Sensors 10(12), 10752-10777 (2010)

10. Sharma, P.: Socio-Economic Implications of Wireless Sensor Networks with Special Reference to its Application in Agriculture. African Journal of Computing \& ICT 6(2) (2013)

11. Park, D.H., Park, J.W.: Wireless sensor network-based greenhouse environment monitoring and automatic control system for dew condensation prevention. Sensors 11(4), 3640-3651 (2011)

12. Carullo, A., Corbellini, S., Parvis, M., et al.: A wireless sensor network for cold-chain monitoring. IEEE Transactions on Instrumentation and Measurement 58(5), 1405-1411 (2009) 